\title{
Conf-950226--42
}

UCRL-JC-120178

PREPRINT

\section{Modeling of Endovascular Patch Welding Using the Computer Program LATIS}

Michael E. Glinsky, Rich A. London, George B. Zimmerman and Steven L. Jacques*

This paper was prepared for submittal to the SPIE's 1995 International Symposium on Lasers and Applications/Biomedical Optics

Laser-Tissue Interaction VI, San Jose, CA

February 4-10, 1995

March 1, 1995

This is a preprint of a paper intended for publication in a journal or proceedings. Since changes may be made before publication, this preprint is made available with the understanding that it will not be cited or reproduced without the permission of the author.

* University of Texas M.D. Anderson Cancer Center Houston, Texas 77030 


\section{DISCLAIMER}

This document was prepared as an account of work sponsored by an agency of the United States Government. Neither the United States Government nor the University of California nor any of their employees, makes any warranty, express or implied, or assumes any legal liability or responsibility for the accuracy, completeness, or usefulness of any information, apparatus, product, or process disclosed, or represents that its use would not infringe privately owned rights. Reference herein to any specific commercial product, process, or service by trade name, trademark, manufacturer, or other wise, does not necessarily constitute or imply its endorsement, recommendation, or favoring by the United States Government or the University of California. The views and opinions of authors expressed herein do not necessarily state or reflect those of the United States Government or the University of California, and shall not be used for advertising or product endorsement purposes. 


\section{DISCLAIMER}

Portions of this document may be illegible in electronic image products. Images are produced from the best available original document. 


\title{
Modeling of endovascular patch welding using the computer program LATIS
}

\author{
Michael E. Glinsky, Richard A. London and George B. Zimmerman \\ Lawrence Livermore National Laboratory \\ Livermore, California 94550
}

Steven L. Jacques

University of Texas, M. D. Anderson Cancer Center

Houston, Texas 77030

\begin{abstract}
A new computer program, LATIS, being developed at Lawrence Livermore National Laboratory is used to study the effect of pulsed laser irradiation on endovascular patch welding. Various physical and biophysical effects are included in these simulations: laser light scattering and absorption, tissue heating and heat conduction, vascular cooling, and tissue thermal damage. The geometry of a patch being held against the inner vessel wall ( $500 \mu \mathrm{m}$ inner diameter) by a balloon is considered. The system is exposed to light pulsed from an optical fiber inside the balloon. A minimum in the depth of damage into the vessel wall is found. The minimum damage zone is about the thickness of the patch material that is heated by the laser. The more ordered the tissue the thinner the minimum zone of damage. The pulse length which minimizes the zone of damage is found to be the time for energy to diffuse across the layer. The delay time between the pulses is determined by the time for the heated layer to cool down. An optimal pulse length exists which minimizes the total time needed to weld the patch to the wall while keeping the thickness of the damaged tissue to less than $100 \mu \mathrm{m}$. For the case that is considered, a patch dyed with light absorbing ICG on the side next to the vessel (thickness of the dyed layer is $60 \mu \mathrm{m}$ ), the best protocol is found to be $65-200 \mathrm{~ms}$ pulses applied over $2 \mathrm{~min}$.
\end{abstract}

Keywords: laser, welding, soldering, endovascular, patch, stent, simulation

\section{INTRODUCTION}

There is general interest in endovascularly welding patches or stents to close aneurysms, to reinforce vessel walls, ${ }^{1}$ and to cover the vessel wall after angioplasty or metal stent deployment. These patches need to be attached to the wall by some means. A possibility is tissue welding or soldering. ${ }^{2}$ To accomplish this, the inside of the vessel wall needs to be heated to a high enough temperature for a long enough time to cause the proteins to unfold; to expose the polar parts of their molecular structure, and then to have those polar parts form hydrogen bonds with the proteins in the patch. A layer no thicker than 100 $\mu \mathrm{m}$ should be "damaged" so that the tissue does not nercrose. ${ }^{3}$ The use of pulsed radiation to control this zone of damage has been suggested. ${ }^{4}$ This paper explores via computer simulation the feasibility of doing it in a realistic situation.

The concept of tissue damage has been quantified in various ways. Properties such as birefringence, ${ }^{5}$ tissue necrosis, tissue whitening, light scattering and contraction ${ }^{6}$ have been used as a metric. The results have indicated a reaction process that can be modeled (to first order) as a single rate process with an energy of activation that varies between 20 to $40 \mathrm{meV}$ depending on how ordered the tissue is. The reaction rate is given by the Arrenhius expression:

$$
k(T)=\frac{k_{B} T}{h} \exp (-\Delta H / R T+\Delta S / R),
$$

where $\Delta H$ is the enthalpy of reaction and $\Delta S$ is the entropy of reaction. The temperature dependence of the reaction rates for various types of tissue are shown in Fig. 1. Notice that the more ordered the tissue the higher the energy barrier that must be surmounted. These measures of damage are assumed to be correlated to the protein unfolding that is necessary for tissue bonding to occur. We emphasize that this is an assumption that should be investigated. It is also an assumption that tissue bonding is a single rate process. It has already been determined that there are at least two rates that contribute to changes in birefringence. ${ }^{5}$ In addition it should be noted that according to this model some tissues will become damaged in $3 \mathrm{hrs}$ at body 
temperature. Since this is obviously not true, there has to be a repair process or other correction to the damage rate which takes the net rate to zero at body temperature.

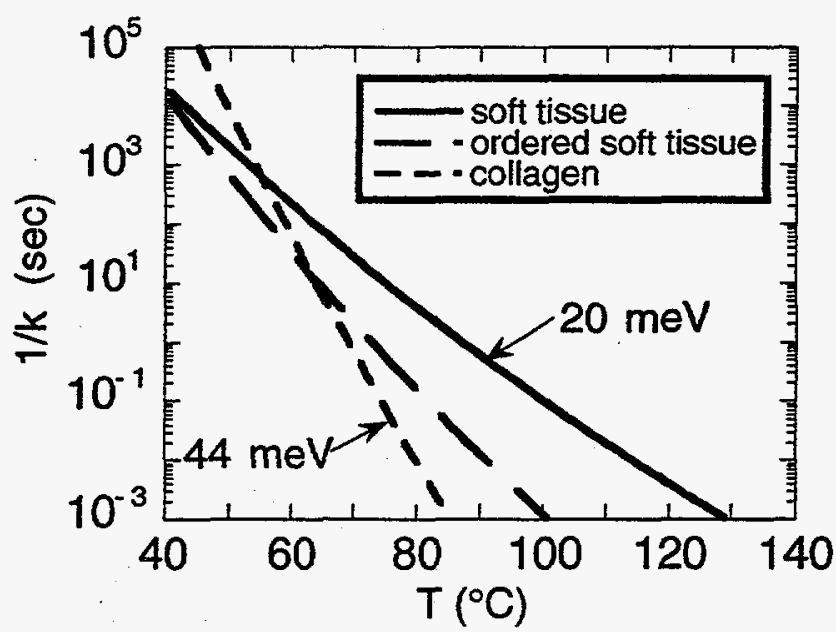

Fig. 1. Tissue damage timescale $(1 / k)$ vs. temperature.

The concept that pulsed energy delivery can lead to a controlled zone of damage is based on the exponential nonlinearity of the reaction rate shown in Eq. (1). If one delivers energy to a volume on a time scale that is greater than or equal to the time for energy to thermally diffuse across the layer, then the temperature will decay as $L^{-d}$ where $d$ is the dimensionality of volume over which the heat is spreading and $L$ is the scale length of the volume. For thermal diffusion it is well known that $L \sim t^{1 / 2}$, where $t$ is the time since the energy was deposited. The number of undamaged protein molecules $N_{u}$ evolves according to the equation

$$
\frac{d N_{u}}{d t}=-k(T) N_{u}
$$

Therefore the number of undamaged molecules evolves as $N_{t o t} \exp (-\Omega)$ where $N_{t o t}$ is the initial number of protein molecules and $\Omega=\int k d t$. What we now wish to find is how the damage index $\Omega$ scales with $L$. This scaling is given by

$$
\Omega=\int k d t \propto L^{2-d} e^{-\left(L / L_{0}\right)^{d}}
$$

where $L_{o}$ is a constant, the factor $L^{2}$ is contributed by $\int d t$ and the factor $L^{-d} e^{-\left(L / L_{o}\right)^{d}}$ is contributed by the reaction rate. Notice that for large enough length scales, $\Omega$ always tends to zero because of the exponential factor. For the small length scales of interest, not enough damage can be done with one pulse. Therefore multiple pulses must be applied to accumulate the damage. The pulses must be separated by enough time - the average temperature must be kept low enough so that the tissue will not become damaged over the course of the treatment.

\section{SIMULATION METHOD}

A new computer code, LATIS (an acronym for LAser TISsue) is being developed at Lawrence Livermore National Laboratory. It is based on our past experience in constructing large computer programs that integrate many physical processes such as: laser propagation, laser energy deposition, hydrodynamics, atomic physics, radiation absorption, radiation emission, and radiation transport. Our final product in the past has been a simulation tool that can predict the results of laser interactions with plasmas. The new code code LATIS is meant to be an analogous tool for laser tissue interactions. The physical processes that have been incorporated in LATIS and tested are: laser light scattering and absorption, tissue heating and heat conduction, vascular cooling of the surrounding tissue, and tissue thermal damage. Other physics such as 
hydrodynamics, diffusive photon transport, evaporative cooling, and radiative cooling are coupled into the code but have not been tested. Planned additions are condensed history Monte Carlo photon transport, elastic wave propagation, material failure, water diffusion, and 3D geometries.

The laser light is propagated via a Monte Carlo transport scheme. The total census of photons is kept a constant, 1000 for the simulations presented in the paper. The photons are split or killed to keep the census number a constant. The scattering is done at random with a Henyey-Greenstein angular distribution. ${ }^{7}$ This distribution is based on the assumption that the size of the scatterers is of order the wavelength of the light (Mie scattering theory). It was originally used to model the scattering of light by interstellar dust. The distribution is determined by two parameters: the scattering coefficient $\mu_{s}$ and the average value of the cosine of the scattering angle $g$. The weight of the photons is decreased as they are absorbed consistent with the absorption coefficient $\mu_{a}$. The weight is decreased down to a user specified value, $10^{-2}$ for our case, at which time the photon is killed. The photons are refracted at the zone (cell) boundaries and both refracted and reflected at region boundaries. This is consistent with the discontinuous change in material properties between different regions and the continuous change in properties of a single material within a region. As a first approximation for the effect of surface roughness the photons are reflected into a $2 \pi$ solid angle (in contrast to a specular reflection) at a specified probability ( $1 \%$ for our simulations).

The energy that is taken out of the photons due to the absorption is deposited into the tissue's thermal energy. The energy is then allowed to diffuse with a zone dependent heat conductivity that can be different along the two directions that define the orientation of the grid. For our simulations we used an isotropic heat conduction.

Tissue damage is accumulated on a zone by zone basis as the local reaction rate $k(T)$ is summed to give the damage integral $\Omega$. The tissue scattering is modified by the damage, changing from the undamaged value $\mu_{s u}$ to the damaged value $\mu_{s d}$ according to the formula

$$
\mu_{s} N_{t o t}=\mu_{s u} N_{u}+\mu_{s d} N_{d} \text {, }
$$

where $N_{d}=N_{t o t}-N_{u}$ and is the number of damaged protein molecules. This allows a soft tissue to whiten as chicken does as it is cooked - the scattering increasing by a factor of seven as the protein collects into clumps. For a structural protein such as collagen the opposite happens - the fibers are melted together as it is damaged, turning it into a jello with scattering that is ten times less than in its undamaged state.

The bulk vascular cooling of the tissue is modeled by an energy source term $Q_{v}$ given by

$$
Q_{v}=A(T)\left(T_{b o d y}-T\right) e^{-\Omega},
$$

where $T_{b o d y}$ is the body temperature and $A(T)$ is a temperature dependent prefactor set to give a cooling time consistent with a blood perfusion rate of $40 \mathrm{ml} / 100 \mathrm{gm} / \mathrm{sec}$ at body temperature. It is multiplied by a factor of four for temperatures above $42^{\circ} \mathrm{C}$ due to a physical dilation of the capillaries. The exact behavior is shown in Fig. 2. The factor $e^{-\Omega}$ in Eq. (5) shuts off the cooling as the tissue is damaged. 


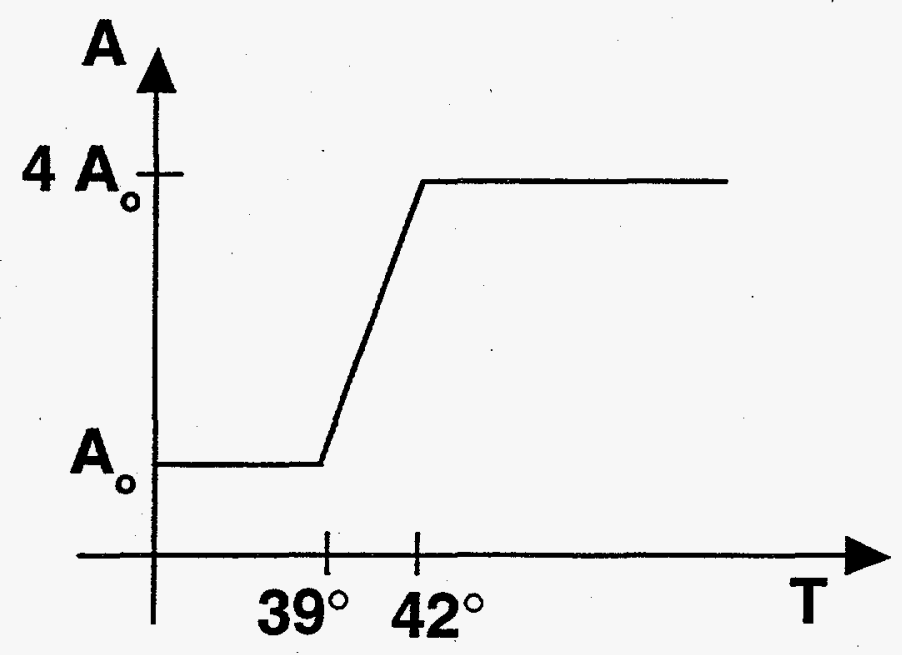

Fig. 2. Increase in the vascular cooling rate due to capillary dilation at elevated temperatures.

\section{RESULTS}

A series of simulations were done using the geometry shown in Fig. 3. For all regions of the simulation a density of 1 $\mathrm{gm} / \mathrm{cc}$ and a heat capacity of $4.18 \mathrm{~J} / \mathrm{gm} /{ }^{\circ} \mathrm{K}$ is used. The other important parameters are shown in Table $\mathrm{I}$. Vascular cooling is only applied to the surrounding tissue. The properties used for the balloon, saline, and fiber were taken from an engineering handbook. ${ }^{8}$ The tissue parameters are generic numbers for soft tissue and visible light. The absorption coefficient of the gel+ICG layer was adjusted so that $1 / 10$ of the laser energy would be absorbed in it. This was done to deposit as much energy as possible at the tissue side of the layer. The laser intensity had the profile shown in Fig. 4. It consisted of a train of square pulses of length $\Delta t$ separated by a delay $\tau$. The energy in the pulse is adjusted so that the maximum temperature at the end of the pulse is $100^{\circ} \mathrm{C}$. Only one pulse is modeled giving a damage integral $\Omega_{1}$. The damage of $N$ pulses is assumed to be additive so that $\Omega=N \Omega_{1}$. The number of pulses was chosen so that the maximum $\Omega$ in the tissue is 10 . The additivity of the damage is not a strictly valid assumption. There is a nonlinear feedback through the effect of the thermal damage on the scattering coefficient. This effect will be the subject of subsequent investigations.

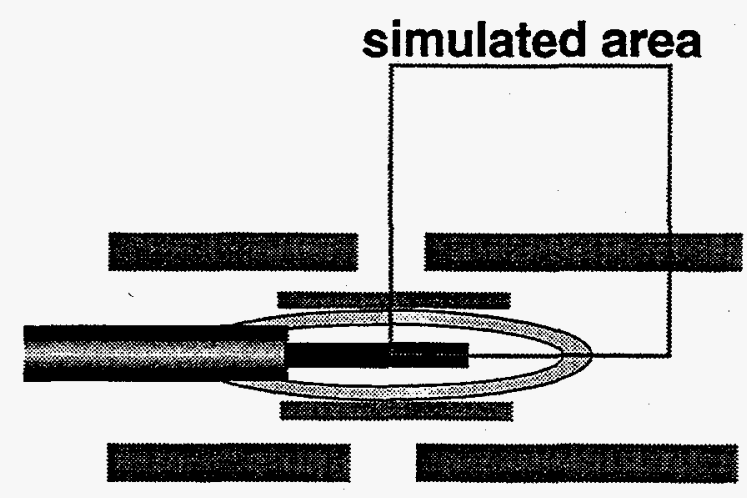

Fig. 3a. Geometry that is simulated. Shown is the simulation area. This area is symmetric about the left vertical line. There is an azimuthal symmetry about the line $r=0$ (lower horizontal line). 


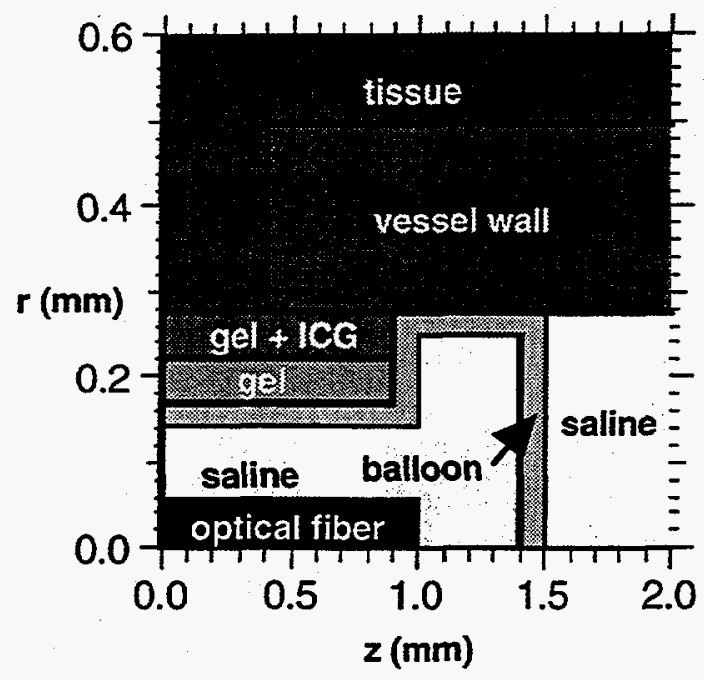

Fig. 3b. Area that is simulated.

\begin{tabular}{|l|l|l|l|l|l|l|}
\cline { 2 - 7 } \multicolumn{1}{c|}{} & $\begin{array}{l}\mu_{\mathrm{a}} \\
\left(\mathrm{cm}^{-1}\right)\end{array}$ & $\begin{array}{l}\mu_{\mathrm{su}} \\
\left(\mathrm{cm}^{-1}\right)\end{array}$ & $\begin{array}{l}\mu_{\mathrm{sd}} \\
\left(\mathrm{cm}^{-1}\right)\end{array}$ & $\mathrm{n}$ & damage model & $\kappa\left(\mathrm{W} / \mathrm{m} /{ }^{\circ} \mathrm{K}\right)$ \\
\hline vessel & 0.3 & 5.0 & 35.0 & 1.37 & $\begin{array}{l}\text { soft tissue or } \\
\text { ordered soft tissue }\end{array}$ & 0.609 \\
\hline gel + ICG & 10.0 & 10.0 & 1.0 & 1.37 & collagen & 0.609 \\
\hline gel & 0.01 & 10 & 1.0 & 1.37 & collagen & 0.609 \\
\hline balloon & & clear & & 1.45 & none & 0.170 \\
\hline saline & & clear & & 1.33 & none & 0.609 \\
\hline fiber & & clear & & 1.5 & none & 0.609 \\
\hline tissue & 0.3 & 5.0 & 35.0 & 1.37 & $\begin{array}{l}\text { soft tissue or } \\
\text { ordered soft tissue }\end{array}$ & 0.609 \\
\hline
\end{tabular}

Table I. Parameters used in the simulation. 


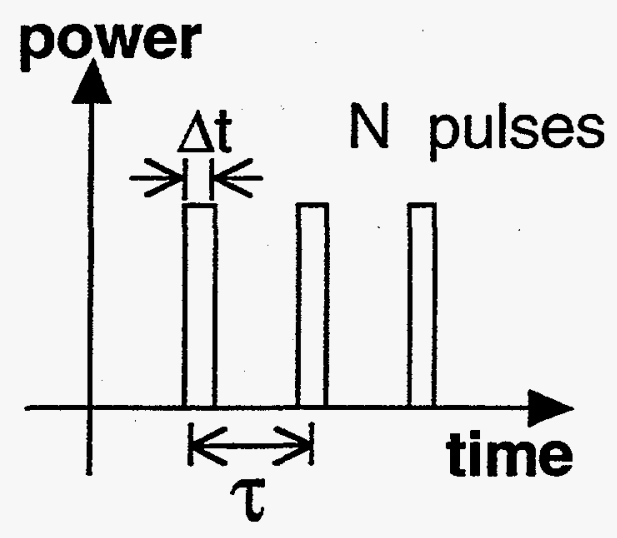

Fig. 4. Laser pulse profile.

The results of these simulations are shown in Figs. 5 and 6. Due to the exponential character of the damage rate, the edge of the damage zones are sharper than the temperature profiles. Notice that the extent of the temperature diffusion increases monotonically with increasing pulse length as expected. In contrast, the zone of damage shows a minimum for 60 $\mathrm{ms}$ pulses. This is more clearly shown in Fig. 7 where the thickness of the damage zone is plotted as a function of the pulse length. The thickness is defined as the radial distance from the outside edge of the patch to the point at which $N_{d} / N_{t o t}=0.5$. The bars indicate the value to which the damage thickness asymptotes for very short pulses. The minimum is due to the nonlinear character of the damage rate. Although the diffusion operator is linear and the contributions of the early part of the pulse to the temperature add to the contributions of the later part of the puise, the damage rate amplifies the contribution of the later part making its shorter length scale dominant. This amplification is larger for the ordered soft tissue leading to a smaller minimum value for the depth of damage.

(a)

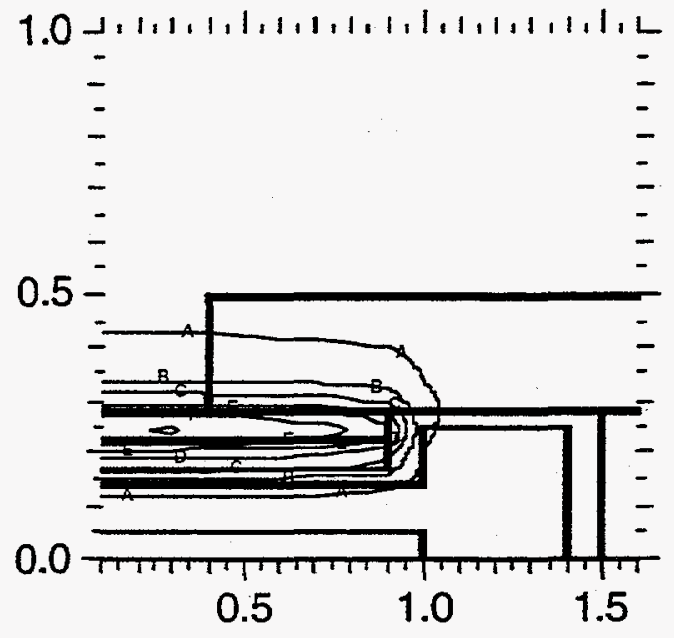

(b)

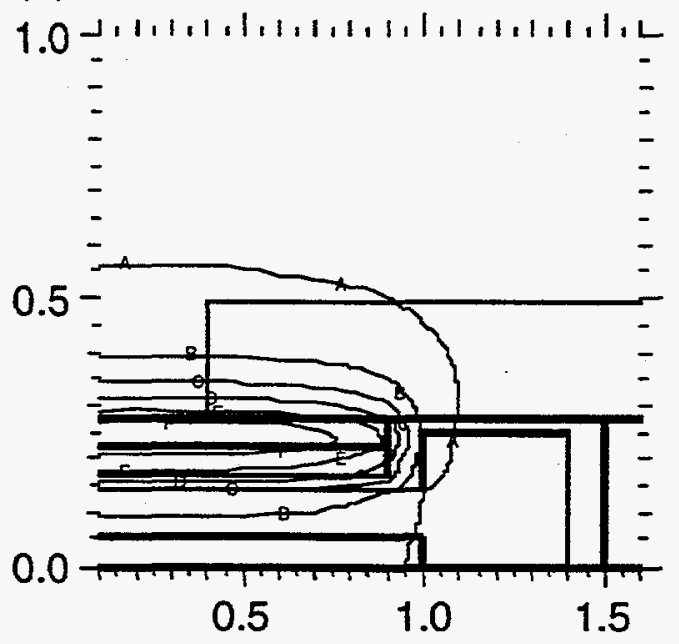


(c)

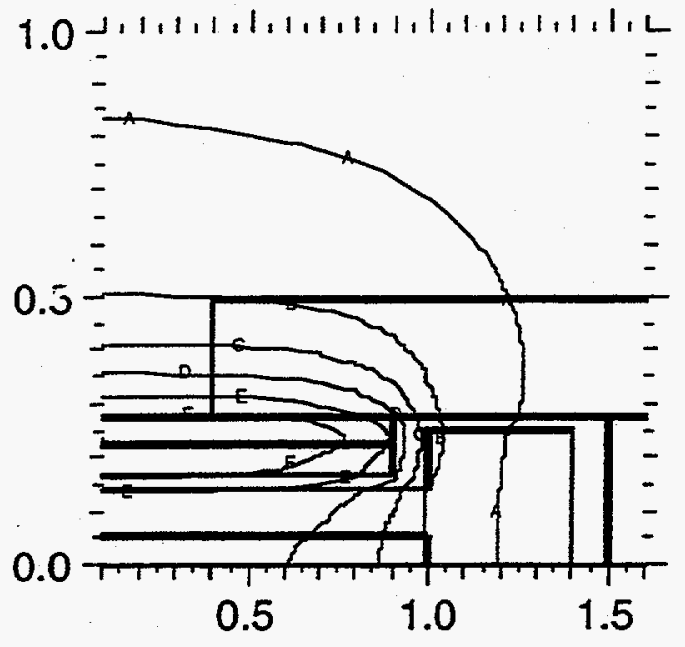

(d)

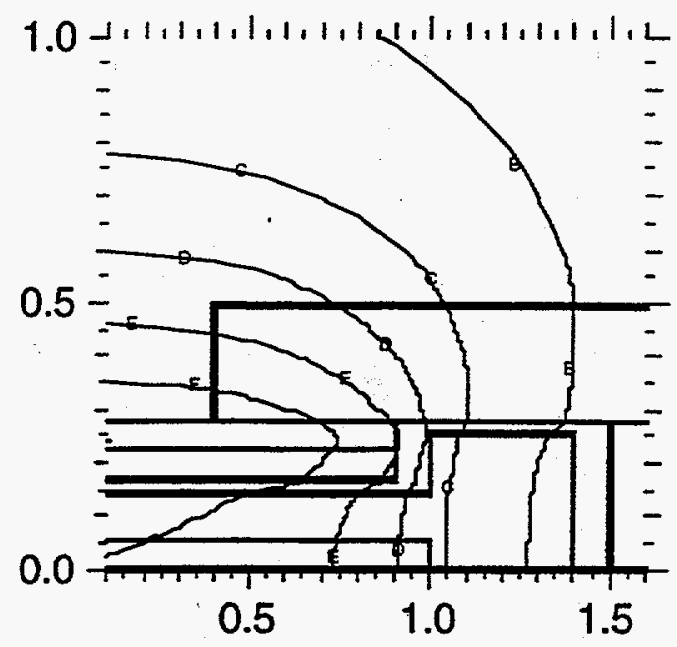

(e)

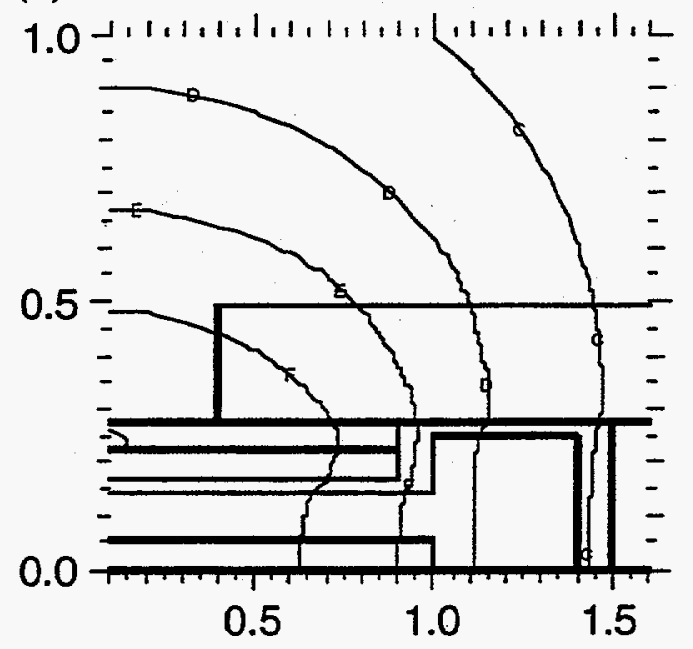

Fig. 5. Temperature profiles at the end of the pulse for different pulse lengths ( $a=20 \mathrm{~ms}, b=60 \mathrm{~ms}, c=200 \mathrm{~ms}, d=600 \mathrm{~ms}, e=2000 \mathrm{~ms}$ ). The contour levels are: $\mathrm{A}=40^{\circ} \mathrm{C}, \mathrm{B}=50^{\circ} \mathrm{C}, \mathrm{C}=60^{\circ} \mathrm{C}, \mathrm{D}=70^{\circ} \mathrm{C}, \mathrm{E}=$ $80^{\circ} \mathrm{C}, \mathrm{F}=90^{\circ} \mathrm{C}, \mathrm{G}=100^{\circ} \mathrm{C}$. The vertical axis is radial and the horizontal axis is axial with distances labeled in $\mathrm{mm}$. 
(a)

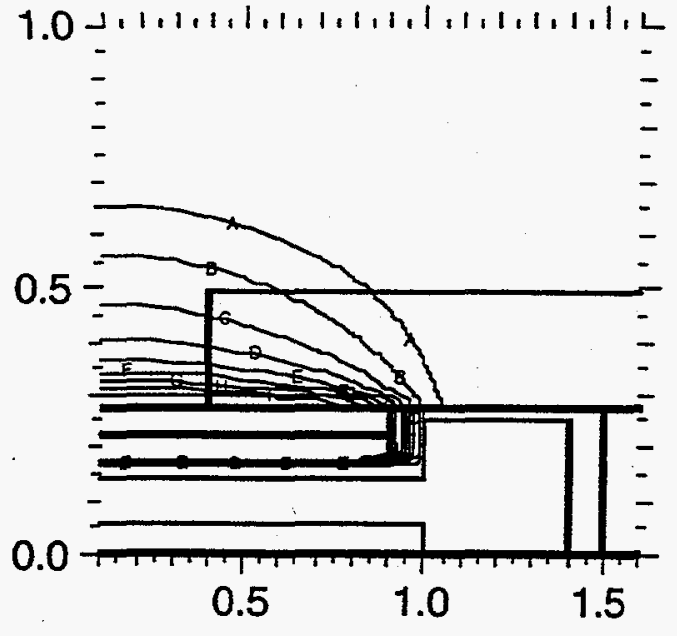

(c)

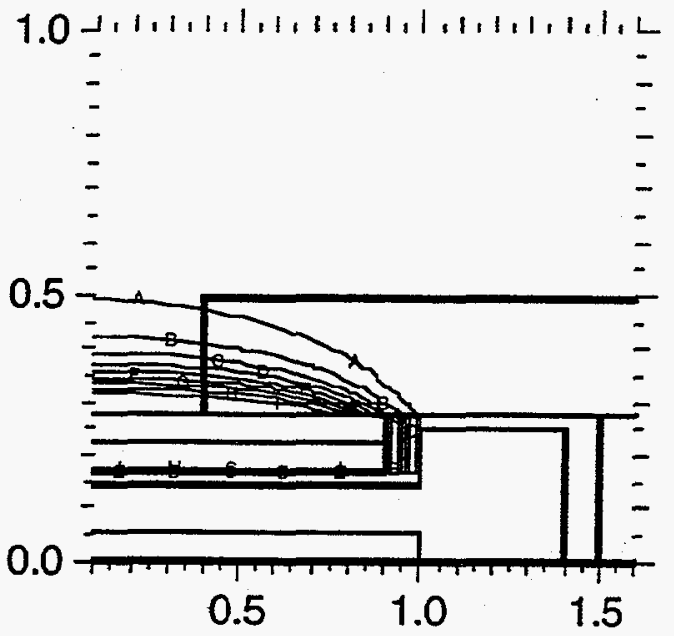

(b)

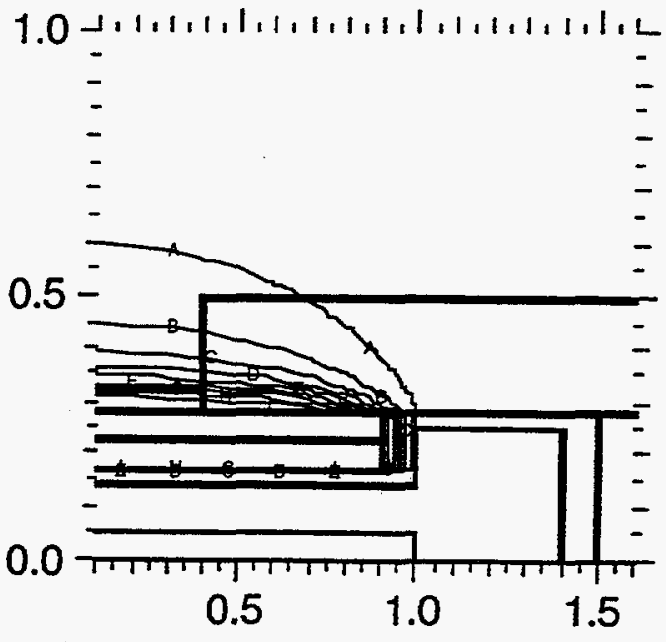

(d)

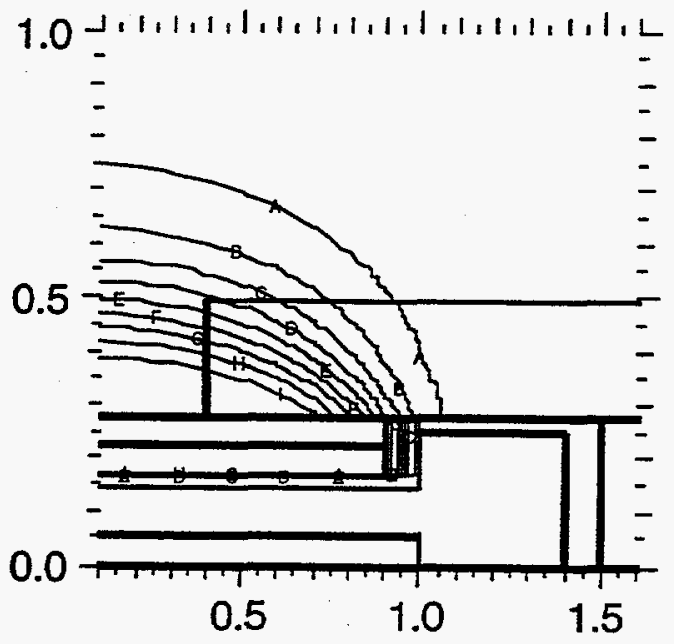


(e)

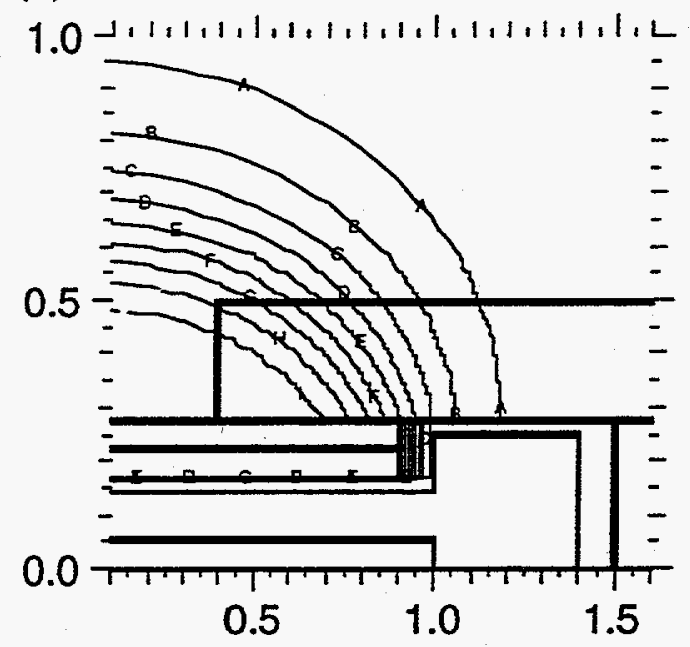

Fig. 6. Amount of damaged tissue at the end of the pulse train $(a=20$ ms, 2035 pulses; $b=60 \mathrm{~ms}, 442$ pulses; $c=200 \mathrm{~ms}, 65$ pulses; $d=$ $600 \mathrm{~ms}, 8$ pulses; $\mathrm{e}=2000 \mathrm{~ms}, 2$ pulses). The contour levels are for $N_{d} / N_{\text {tot }}: \mathrm{A}=0.1, \mathrm{~B}=0.2, \mathrm{C}=0.3, \mathrm{D}=0.4, \mathrm{E}=0.5, \mathrm{~F}=0.6, \mathrm{G}=$ $0.7, \mathrm{H}=0.8, \mathrm{I}=0.9$. The vertical axis is radial and the horizontal axis is axial with distances labeled in $\mathrm{mm}$.

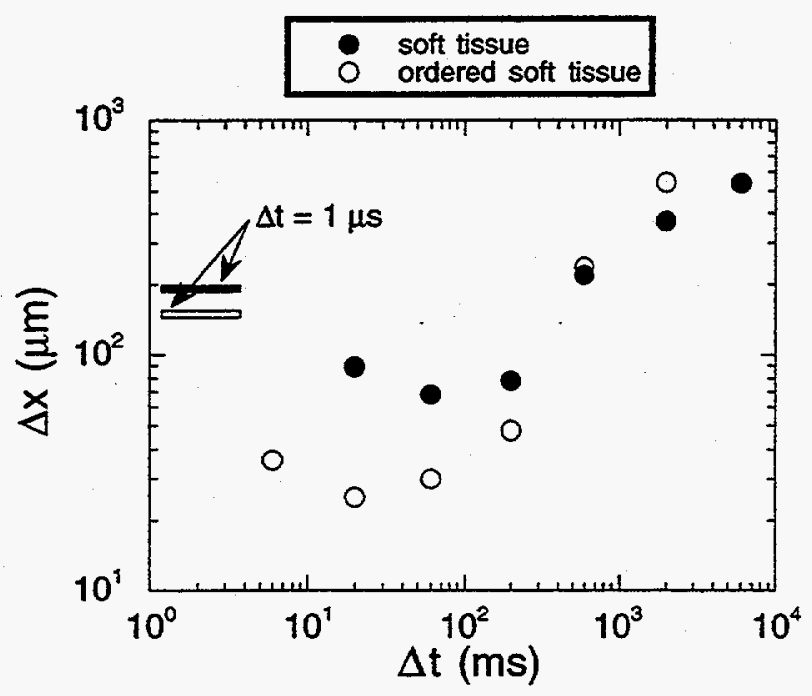

Fig. 7. Depth of damage zone vs. pulse width.

The pulse delay $\tau$ is determined by continuing the simulation out to long times. The condition that we take is that the temperature rise from $N$ pulses at the total treatment time $N \tau$ should be less than $\Delta \mathrm{T}=3^{\circ} \mathrm{C}$, that is

$$
\left[T_{\max }(t=N \tau)-T_{b o d y}\right] N=\Delta T
$$


An example is shown in Fig. 8. A summary of the results of the simulations for soft tissue is given in Table II. Note that there is an optimal $\Delta \mathrm{t}=200 \mathrm{~ms}$ which minimizes $N \tau$ while keeping $\Delta \mathrm{x}<100 \mu \mathrm{m}$.

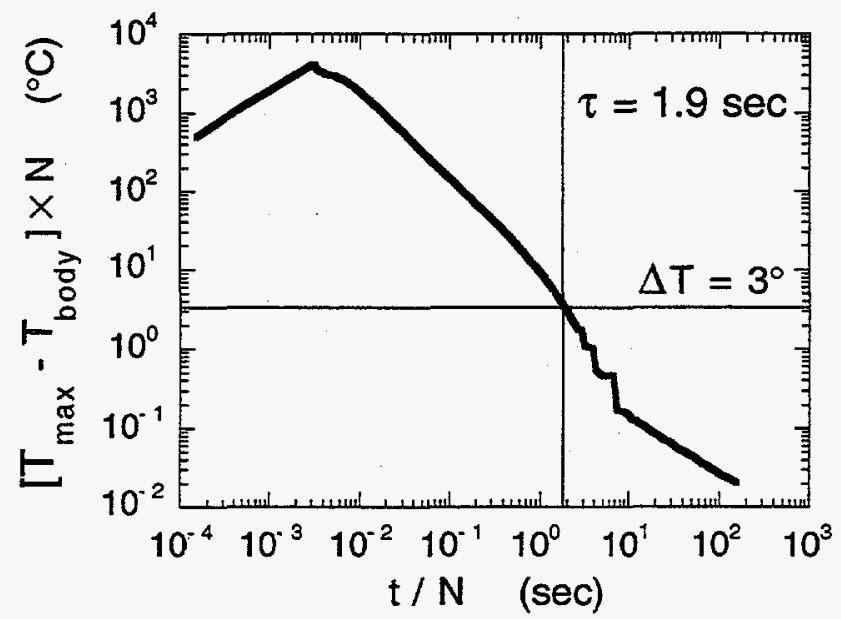

Fig. 8. Average temperature rise vs. pulse delay $(\Delta \mathrm{t}=200 \mathrm{~ms})$.

\begin{tabular}{|l|l|l|l|l|}
\hline$\Delta \mathrm{t}(\mathrm{ms})$ & $\mathrm{N}$ & $\tau(\mathrm{sec})$ & $\mathrm{N} \tau(\min )$ & $\Delta \mathrm{x}(\mu \mathrm{m})$ \\
\hline 20 & 2035 & 1.7 & 57 & 89 \\
\hline 60 & 442 & 0.54 & 4.0 & 68 \\
\hline 200 & 65 & 1.9 & 2.1 & 78 \\
\hline 600 & 8 & 15 & 2.0 & 220 \\
\hline 2000 & 2 & 33 & 1.1 & 371 \\
\hline 6000 & 1 & 47 & 0.8 & 540 \\
\hline
\end{tabular}

Table I. Parameters used in the simulation.

\section{DISCUSSIONS AND CONCLUSIONS}

It is possible to control the zone of damage by use of pulsed laser irradiation. The minimum size of this zone is determined by the thickness of the layer over which the laser energy is deposited. The delay between pulses is determined by the time it takes the tissue to cool down. For a $60 \mu \mathrm{m}$ thick collagen layer dyed with ICG, one can limit the zone of damage to $80 \mu \mathrm{m}$ by applying $65-200 \mathrm{~ms}$ pulses over the course of $2 \mathrm{~min}$. This treatment protocol minimizes the treatment time while keeping the zone of damage to less than $100 \mu \mathrm{m}$ in thickness.

\section{ACKNOWLEDGMENTS}

This work was performed under the auspices of the U.S. Department of Energy by the Lawrence Livermore National Laboratory under contract W-7405-ENG-48. 


\section{REFERENCES}

1. K.W. Gregory and J. Grunkemeier, "Internal elastic lamina replacement with a new elastin stent biomaterial," Circulation, Vol. 90, 1994.

2. K. Sensaki, T. Arai and S. Tanaka, "Laser patch welding: experimental study for application to endoscopic closure of bronchopleural fistula, a preliminary report," Lasers in Surgery and Medicine, Vol. 16, pp. 24-33, 1995.

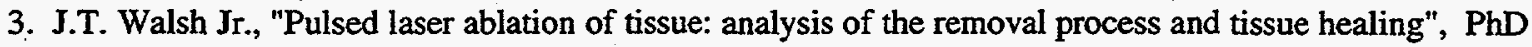
dissertation, MTT Archives, Cambridge MA, 1988.

4. R.R. Ailderson and J.A. Parrish, "Selective photothermalysis: precise microsurgery by selective absorption of pulsed radiation," Science, Vol. 220, pp. 524-527, April 1983.

5. D.J. Maitland and J.T. Walsh Jr., "Quantitative measurement of linear birefringence during the heating of native collagen", Lasers in Surgery and Medicine, Wiley, New York, in press.

6. S. L. Jacques, private communication.

7. L.G. Henyey and J.L. Greenstein, "Diffuse radiation in the galaxy," Astrophysical Journal, Vol. 93, pp 70-83, 1941.

8. D.D. Pollack, Physical Properties of Materials for Engineers, 2nd edition, CRC Press, Boca Raton, 1993. 